\title{
Ancoragem da prata em substratos cerâmicos para tratamento de água de consumo
}

\section{(Anchoring of silver in ceramic substrates for consumer water treatment)}

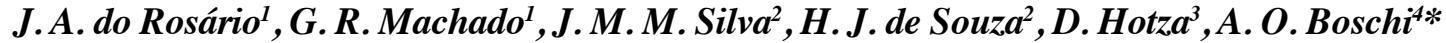 \\ ${ }^{1}$ Universidade do Estado de Santa Catarina, CAV, \\ Departamento de Engenharia Ambiental e Sanitária, Lages, SC, Brasil \\ ${ }^{2}$ Universidade do Extremo Sul Catarinense, Departamento de Engenharia Química, Criciúma, SC, Brasil \\ ${ }^{3}$ Universidade Federal de Santa Catarina, Departamento de Engenharia Química, Florianópolis, SC, Brasil \\ ${ }^{4}$ Universidade Federal de São Carlos, Departamento de Engenharia de Materiais, São Carlos, SP, Brasil
}

\begin{abstract}
Resumo
A fabricação de vasos cerâmicos impregnados com prata possibilita o acesso à água potável de uma forma barata e com fabricação relativamente simples. Este estudo teve como objetivo promover a modificação superficial de filtros cerâmicos utilizando APTES e EDTA como agentes ancoradores para melhorar a impregnação da prata e a eficiência e durabilidade dos filtros, avaliando-se diferentes rotas de modificação superficial. A ancoragem e adsorção da prata foram analisadas por espectroscopia FTIR e absorção atômica, e a água filtrada foi analisada quanto à presença de Escherichia coli. Os resultados obtidos demonstraram que a ancoragem melhorou a captura da prata pela cerâmica, em especial com o EDTA, não importando a ordem nas etapas de impregnação. Todos os substratos impregnados com prata, ancorados ou não, apresentaram ausência de E. coli, demonstrando que o procedimento de impregnação atingiu o efeito bactericida esperado e que a ancoragem não interferiu na atuação microbiológica dos filtros.

Palavras-chave: filtração, água potável, ancoragem de prata, substratos cerâmicos.
\end{abstract}

\begin{abstract}
The manufacture of ceramic vessels impregnated with silver enables access to drinking water in an inexpensive and relatively simple way. This study aimed to promote the surface modification of ceramic filters using APTES and EDTA as anchoring agents to improve the impregnation of silver and the efficiency and durability of the filters, evaluating different routes of surface modification. Silver anchoring and adsorption were analyzed by FTIR and atomic absorption spectroscopy, and the filtered water was analyzed for the presence of Escherichia coli. The results showed that the anchoring improved the silver capture by the ceramic, especially with the EDTA, regardless of the order in the impregnation steps. All substrates impregnated with silver, anchored or not, showed the absence of E. coli, demonstrating that the impregnation procedure reached the expected bactericidal effect and that the anchorage did not interfere in the microbiological performance of the filters.
\end{abstract}

Keywords: filtration, drinking water, silver anchoring, ceramic substrates.

\section{INTRODUÇÃO}

O acesso à água adequada para consumo ainda consiste de um dos problemas atuais mais difíceis de serem superados. Estima-se que no mundo cerca de 748 milhões de pessoas não consomem água dentro dos padrões aceitáveis [1] e que no Brasil até 2013 somente 82,5\% dos brasileiros tinham acesso à água tratada [2]. Neste sentido, a fabricação de filtros cerâmicos impregnados com prata tem sido utilizada como uma opção de tratamento doméstico da água. Projetos como o Potters for Peace, concebido nos Estados Unidos, aplicado inicialmente na Nicarágua e espalhado para diversos países, conseguiram obter filtros cerâmicos de baixo custo e de fabricação relativamente acessível [3]. O uso de cerâmicas

* (D) https://orcid.org/0000-0003-0233-2140 porosas em filtrações apresenta como principais vantagens a estabilidade química e térmica, não interferindo no sabor ou aspecto da água. A sua porosidade faz com que a água atravesse o substrato a uma vazão adequada (normalmente entre 1 e $2 \mathrm{~L} / \mathrm{h}$, para a finalidade de filtração de água) e ao mesmo tempo seja capaz de reter sedimentos suspensos e até parte dos microrganismos presentes. Filtros cerâmicos porosos sem qualquer associação a agentes antimicrobianos podem ser capazes de remover mais de $90 \%$ da Escherichia coli presente na água bruta [4].

O uso da prata como agente bactericida, por outro lado, permite a aniquilação das bactérias retidas no filtro, o que evita a passagem dos patógenos acumulados na matriz cerâmica e uma possível contaminação da água passante. Acreditase que a atuação da prata sobre bactérias seja derivada da captura dos íons $\mathrm{Ag}^{+}$pelo microrganismo, inibindo diversas funções celulares da bactéria e produzindo espécies reativas 
que a atacam [5]. Os íons de prata também podem interagir com o DNA, impedindo a replicação da célula [6]. Contudo, estudos têm demonstrado que a destruição das bactérias se dá somente pela interação com a superfície metálica (e o contato com os íons), sem a necessidade de liberação da prata em solução. Estudos como [7] têm explorado a formação de estruturas encapsuladas em suportes (tipo core-shell) de nanopratas combinadas com íons de prata, o que permitiria um efeito bactericida sinérgico das duas espécies, com a vantagem de prevenir a lixiviação de partículas solúveis de prata, evitando efeitos de toxicidade sobre a água. Assim, há indícios de que a prata pode promover a descontaminação da água sem a necessidade de ser liberada na mesma, evitando dessa forma o consumo de resíduos do metal e possíveis problemas decorrentes que já foram reportados em estudos envolvendo cobaias $[8,9]$ e também seres humanos [10]. Portanto, ainda se faz necessária a busca por métodos que evitem o carreamento da prata pela água passante, melhorando a eficiência destes filtros quanto à atividade bactericida, e permitindo o aumento do seu tempo de vida útil. Se as nanopartículas de prata se adsorvem à superfície cerâmica através de ligações fracas, como por forças de van der Waals, elas podem ser lixiviadas mais facilmente para a água durante a filtração, o que prejudica a qualidade da água com resíduos de prata, como também diminui a vida útil do filtro quanto ao seu papel descontaminante. Isto pode ser evitado com o uso de substâncias ancoradoras, que façam uma ponte de ligação forte entre as nanopartículas metálicas e o substrato cerâmico.

Materiais que dispõem de grupos hidroxilados em suas superfícies, como as argilas, podem reagir com agentes funcionalizadores, permitindo modificações químicas de suas estruturas por meio de 3 mecanismos possíveis: através de reações de superfície com os silanos, ou por reações de troca iônica em seus meios interlamelares, ou ainda por meio de processos sol-gel [11]. Segundo o estudo [12], a imobilização de nanopartículas de prata em cerâmicas porosas com o uso do 3-aminopropiltrietoxissilano (APTES) comprovou uma forte atuação antimicrobiana sobre a Escherichia coli, sem observar qualquer perda da nanoprata após armazenamento e diferentes tipos de lavagens. $\mathrm{O}$ ácido etilenodiamino tetra-acético (EDTA), por sua vez, é uma molécula capaz de formar estruturas quelantes com metais e, ainda que nunca se tenha reportado estudos de ancoragem com o seu uso, a substância já foi utilizada na modificação superficial de sepiolitas, obtendo-se uma melhora na adsorção de fenóis e derivados em relação ao silicato bruto [13]. Com isto, os objetivos deste trabalho são avaliar a utilização de substâncias potencialmente ancoradoras das nanopartículas de prata na cerâmica e, com isto, tentar obter uma melhor fixação da prata nos substratos, promovendo uma liberação controlada e segura da mesma na água destinada ao consumo e aumentando com isto a durabilidade dos substratos filtrantes.

\section{MATERIAIS E MÉTODOS}

Substratos cerâmicos filtrantes: para este estudo, foram utilizados 8 substratos cerâmicos comerciais (Cerâmica Stefani), cuja composição foi baseada em argila caulinita e em diatomáceas. As peças foram cilíndricas (com cerca de $90 \mathrm{~mm}$ de altura, $47 \mathrm{~mm}$ de diâmetro externo e $4,0 \mathrm{~mm}$ de espessura) e podiam ser acopladas a diferentes tipos de vasos filtrantes de duplo compartimento disponíveis no mercado, como os de polipropileno ou de cerâmica vermelha. Os substratos foram previamente testados quanto à absorção e vazão de água, obtendo-se valores de $40,67 \%$ e $2,07 \mathrm{~L} / \mathrm{h}$, respectivamente. Isto indicou que as peças foram adequadas para o uso em filtração de água.

Ancoragem da prata: para os testes de ancoragem da prata, foi testado o uso do 3-aminopropiltrietoxissilano (APTES, Sigma-Aldrich, pureza >99\%) e do ácido etilenodiamino tetra-acético (EDTA, Synth, pureza $>99,4 \%$ ) para exercerem o papel de substâncias ancoradoras da prata na superfície cerâmica. A ancoragem foi inicialmente realizada sobre os substratos cerâmicos pulverizados (passantes em malha 200 mesh) para facilitação das análises posteriores. Inicialmente, foram preparadas as soluções ancoradoras (com APTES ou EDTA) em concentrações de $1 \%$ (em massa) e dispersos $10 \mathrm{~g}$ dos pós dos substratos nas soluções. A mistura foi mantida sob agitação por $2 \mathrm{~h}$ em temperatura ambiente. A impregnação da prata foi, por sua vez, realizada via imersão em $50 \mathrm{~mL}$ de solução de prata nanocoloidal comercial (TNS) diluída a $100 \mathrm{mg} / \mathrm{L}$. Após o tempo de contato de $24 \mathrm{~h}$, os pós foram separados das soluções remanescentes por filtração

Tabela I - Descrição dos ensaios de ancoragem da prata e respectivas amostras.

[Table I - Description of silver anchoring tests and respective samples.]

\begin{tabular}{ccc}
\hline Teste & Amostra & Descrição \\
\hline 1 & S+Ag & Imersão do substrato em solução de nanoprata \\
2 & S+EDTA & Imersão do substrato em solução de EDTA \\
3 & $($ EDTA $/ A g)+S$ & Mistura das soluções de EDTA e nanoprata $\rightarrow$ Imersão do substrato \\
4 & $($ EDTA/S $)+A g$ & Imersão do substrato em solução de EDTA $\rightarrow$ Imersão em solução de nanoprata \\
5 & S+APTES & Imersão do substrato em solução de APTES \\
6 & $($ APTES/Ag) + S & Mistura das soluções de APTES e nanoprata $\rightarrow$ Imersão do substrato \\
7 & $($ APTES/S $)+A g$ & Imersão do substrato em solução de APTES $\rightarrow$ Imersão em solução de nanoprata \\
\hline
\end{tabular}




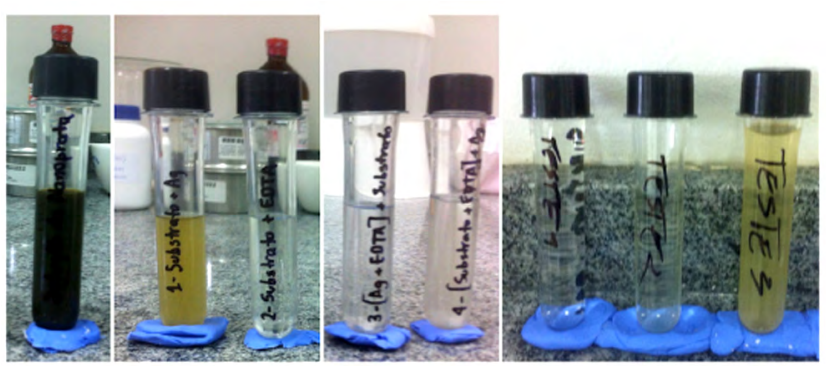

Figura 1: Imagens de amostras das soluções remanescentes dos ensaios de impregnação de prata (da esquerda para a direita): 0) solução de nano-Ag; 1) S+Ag (não ancorado); 2) S+EDTA; 3) (EDTA/Ag)+S; 4) (EDTA/S)+Ag; 5) S+APTES; 6) (APTES/ $\mathrm{Ag})+\mathrm{S} ;$ e 7) (APTES/S)+Ag.

[Figure 1: Samples images of the remaining solutions of the silver impregnation tests (from left to right): 0) nano-Ag solution; 1) $S+A g$ (not anchored); 2) $S+E D T A ; 3)(E D T A / A g)+S$; 4) (EDTA/ $S)+A g$; 5) $S+A P T E S$; 6) $(A P T E S / A g)+S$; and 7) $(A P T E S / S)+A g$.

a vácuo e secos em estufa a $60{ }^{\circ} \mathrm{C}$. Foi testada a ordem da sequência entre os tratamentos (Tabela I) para avaliar qual resultava em uma melhor fixação da prata. É importante observar que a coloração das soluções remanescentes das impregnações (Fig. 1) já indicou diferenças na captação de prata (de solução mais enegrecida) nos substratos ancorados em relação ao não ancorado ( $\mathrm{S}+\mathrm{Ag})$. Posteriormente, os testes que resultaram na melhor fixação da prata foram selecionados para serem reproduzidos sobre os substratos inteiros. Os procedimentos e relações mássicas se mantiveram equivalentes ao processo com os pós, com exceção dos volumes das soluções, que foram aumentadas para $600 \mathrm{~mL}$ para garantir a imersão da peça inteira. Após cada procedimento de impregnação, os substratos foram escorridos por pelo menos $24 \mathrm{~h}$ e mantidos em estufa a $60{ }^{\circ} \mathrm{C}$ por $2 \mathrm{~h}$. O aquecimento, além de promover a secagem das peças, também garantiu as reações de hidrólise necessárias para a modificação das superfícies por silanização [11]. Todos os ensaios foram realizados em ambiente protegido da luz e temperatura controlada de $25 \pm 2{ }^{\circ} \mathbf{C}$.

Filtração de água: os substratos que apresentaram os melhores resultados de adsorção da prata seguiram para os testes de filtração. Foram utilizadas amostras de água bruta proveniente do Rio Caveiras, captado pela Estação de Tratamento de Água de Lages/SC, cuja análise microbiológica prévia resultou em $350 \mathrm{NMP} / 100 \mathrm{~mL}$ quanto à presença de Escherichia coli, o que indicou a sua contaminação e inadequação para consumo direto. Amostras de $500 \mathrm{~mL}$ de água bruta foram passadas pelos substratos previamente selecionados (Tabela II).

Caracterizações: as soluções remanescentes dos procedimentos de ancoragem e impregnação foram analisadas por espectroscopia de absorção atômica (Agilent, 270FS AA) para quantificar a prata que foi adsorvida na cerâmica por intermédio ou não da substância ancoradora. A concentração de prata em fase líquida foi determinada em triplicata. A quantidade de prata adsorvida na fase sólida foi calculada pela Eq. A, sendo que $Q_{e}(\mathrm{mg} / \mathrm{g})$ e $\mathrm{C}_{\mathrm{e}}(\mathrm{mg} / \mathrm{L})$ são as concentrações de prata adsorvida em fase sólida e em fase líquida, respectivamente, $\mathrm{C}_{0}(\mathrm{mg} / \mathrm{L})$ é a concentração inicial de prata, $\mathrm{m}_{\mathrm{s}}(\mathrm{mg})$ é a massa de substrato e V (L) o volume da solução:

$$
\mathrm{Q}_{\mathrm{e}}=\frac{\left(\mathrm{C}_{0}-\mathrm{C}_{\mathrm{e}}\right) \cdot \mathrm{V}}{\mathrm{m}_{\mathrm{s}}}
$$

Já as amostras em pó foram caracterizadas por espectroscopia no infravermelho com transformada de Fourier (FTIR, Shimadzu, IR Prestige 21) para avaliar as ligações entre a cerâmica, a substância ancoradora e a prata. Finalmente, as amostras de água obtidas dos ensaios de filtração com os substratos foram avaliadas quanto ao número de colônias da bactéria Escherichia coli, representando o teor de coliformes termotolerantes presentes na água e o poder descontaminante de cada substrato. Para a análise microbiológica, as amostras de água foram filtradas separadamente em filtros de membrana, que depois foram transferidos para a superfície de placas de Agar Base m-FC (meio basal seletivo para isolamento de coliformes) e posteriormente submergidos em banhos de imersão e incubados a $44,5^{\circ} \mathrm{C}$. Após $24 \mathrm{~h}$, os coliformes fecais presentes no meio seletivo cresceram como colônias de coloração azul, podendo ser quantificadas por contagem direta.

\section{RESULTADOS E DISCUSSÃO}

Os espectros de FTIR obtidos a partir dos substratos em estudo são apresentados na Fig. 2. Observou-se que, em ambos os casos, houve algumas modificações dos espectros dos substratos ancorados em relação ao substrato original, indicando que a ancoragem causou modificações químicas na estrutura cerâmica a partir dos

Tabela II - Descrição dos ensaios de filtração de água e respectivas amostras.

[Table II - Description of water filtration tests and respective samples.]

\begin{tabular}{ccc}
\hline Teste & Amostra & Descrição \\
\hline 1 & $\mathrm{~A}_{\mathrm{S}}$ & Controle: água filtrada em substrato bruto (não ancorado e sem prata) \\
2 & $\mathrm{~A}_{\mathrm{S}+\mathrm{Ag}}$ & Água filtrada em substrato impregnado com prata, mas não ancorado \\
3 & $\mathrm{~A}_{\mathrm{S}+\mathrm{EDTA}+\mathrm{Ag}}$ & Água filtrada em substrato ancorado com EDTA e impregnado com prata* \\
4 & $\mathrm{~A}_{\mathrm{S}+\mathrm{APTES}+\mathrm{Ag}}$ & Água filtrada em substrato ancorado com APTES e impregnado com prata* \\
\hline * ancoragem de melhor performance prévia. &
\end{tabular}


dois reagentes. Pode-se destacar o alargamento das bandas por volta de $3440 \mathrm{~cm}^{-1}$, que correspondeu a alterações no grupo funcional $\mathrm{OH}$ (presente na superfície da camada octaédrica da caulinita) após funcionalização superficial.
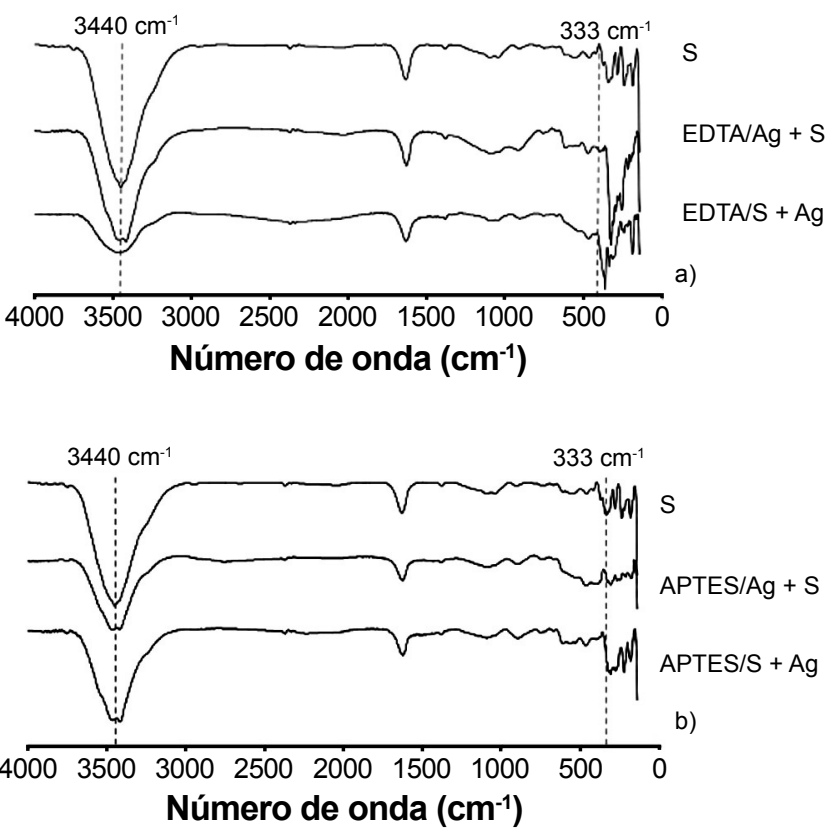

Figura 2: Espectros de FTIR dos substratos ancorados com: a) EDTA; e b) APTES.

[Figure 2: FTIR spectra of substrates anchored with: a) EDTA; and b) APTES.]

Tabela III - Quantidade de prata adsorvida nos substratos em estudo.

[Table III - Amount of silver adsorbed on the substrates under study.]

\begin{tabular}{ccc}
\hline & \multicolumn{2}{c}{$\begin{array}{c}\text { Concentração de prata em fase } \\
\text { sólida (Qe) }\end{array}$} \\
Amostra & \multicolumn{2}{c}{$\begin{array}{c}\text { Substrato } \\
\text { inteiro }\end{array}$} \\
\hline S+Ag & $0,48^{\mathrm{a}}$ & $0,26^{\mathrm{a}}$ \\
S+EDTA & nd & - \\
$($ EDTA $/ \mathrm{Ag})+\mathrm{S}$ & $0,96^{\mathrm{b}}$ & $0,36^{\mathrm{b}}$ \\
(EDTA/S)+Ag & $0,95^{\mathrm{b}}$ & - \\
S+APTES & $\mathrm{nd}$ & - \\
$($ APTES/Ag) $+\mathrm{S}$ & $0,96^{\mathrm{b}}$ & - \\
(APTES/S)+Ag & $0,97^{\mathrm{b}}$ & $0,33^{\mathrm{c}}$ \\
\hline
\end{tabular}

Nota: médias seguidas pela mesma letra não diferem entre si, pelo teste de Tukey a $5 \%$ de probabilidade; $n d$ - não detectado.
Lv et al. [12] analisaram os espectros FTIR de APTES puro e APTES impregnado com nanopartículas de prata; entre 3356 e $3298 \mathrm{~cm}^{-1}$, observaram um deslocamento e aumento de intensidade de uma banda originalmente atribuída à ligação $\mathrm{N}-\mathrm{H}$, devido à formação de ligação $\mathrm{N}-\mathrm{Ag}$. No entanto, no presente trabalho, essa modificação não foi observada, provavelmente devido à absorção muito intensa do material cerâmico [12]. Já as ligações com metais costumam apresentar bandas de absorção na região de impressão digital. Desta forma, destacamse os deslocamentos dos picos de $468 \mathrm{~cm}^{-1}$, atribuídos à presença de prata diretamente na caulinita [14], para a região em torno de $333 \mathrm{~cm}^{-1}$, o que indicou a conexão da prata por intermédio das moléculas ancoradoras em ambos os tratamentos.

Os resultados de adsorção da prata nos substratos em estudo (Tabela III), por sua vez, indicaram primeiramente que a captura da prata após os processos de ancoragem foi muito superior em relação à peça não tratada, tanto com o EDTA como com o APTES. Percebeu-se então que ambas as cerâmicas ancoradas promoveram uma maior fixação da prata, tendo-se assim a comprovação de que o processo de ancoragem atingiu o objetivo esperado. Não foi observada diferença significativa sobre a existência de uma melhor rota sequencial de ancoragem/impregnação, mas ainda assim foram selecionados os procedimentos de melhor resultado no tratamento das peças inteiras. $\mathrm{Na}$ comparação entre os processos de ancoragem com cada reagente, foi observada diferença estatística significativa na impregnação com o substrato inteiro, e a ancoragem com EDTA foi a que obteve o melhor resultado. Isso tem uma implicação muito positiva, pois demonstra que o processo de ancoragem pode ser realizado através de um reagente mais acessível (EDTA), estabelecendo uma maior captação da prata na superfície do substrato.

Quanto à filtração das amostras de água contaminadas, a Tabela IV traz os resultados obtidos a partir dos diferentes substratos. Percebeu-se que todas as amostras filtradas em substratos tratados com prata, sejam eles ancorados ou não, apresentaram ausência de coliformes termotolerantes em comparação com o substrato sem prata (Fig. 3), atendendo desta forma aos padrões de qualidade para água potável, estabelecidos pela Portaria $\mathrm{N}^{\mathrm{o}} 518$ [15]. Portanto, tem-se que o processo de impregnação da prata nos substratos foi satisfatório quanto à desinfecção da água na filtração, e não houve interferência causada pelo processo de ancoragem. Os resultados presentes foram equivalentes aos procedimentos e valores encontrados na literatura sobre impregnação de prata coloidal em substratos inorgânicos, aplicados ao tratamento de água

Tabela IV - Análise microbiológica das amostras de água filtradas a partir dos diferentes substratos.

[Table IV - Microbiological analysis of filtered water samples from different substrates.]

\begin{tabular}{lcccc}
\hline Análise & $\mathrm{A}_{\mathrm{S}}$ & $\mathrm{A}_{\mathrm{S}+\mathrm{Ag}}$ & $\mathrm{A}_{\mathrm{S}+\mathrm{EDTA}+\mathrm{Ag}}$ & $\mathrm{A}_{\mathrm{S}+\mathrm{APTES}+\mathrm{Ag}}$ \\
\hline E. coli $(\mathrm{NMP} / 100 \mathrm{~mL})$ & $1,6.10^{1}$ & Ausente & Ausente & Ausente \\
\hline NMP - número mais provável. & & & &
\end{tabular}




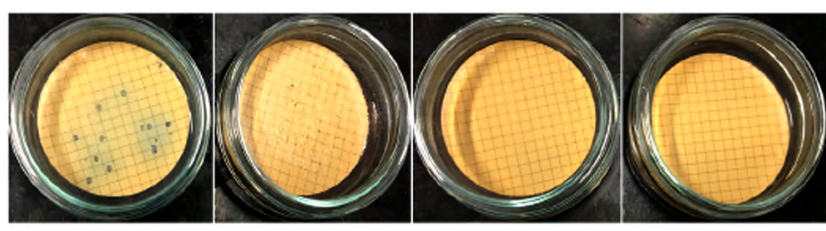

Figura 3: Imagens para contagem das colônias de E. coli a partir dos testes de filtração (da esquerda para a direita): $A_{S} ; A_{S+A g}$; $\mathrm{A}_{\mathrm{S}+\mathrm{EDTA}+\mathrm{Ag}} ;$ e $\mathrm{A}_{\mathrm{S}+\mathrm{APTES}+\mathrm{Ag}}$.

[Figure 3: Images for E. coli colonies count from the filtration tests (from left to right): $A_{S} ; A_{S+A g} ; A_{S+E D T A+A g} ;$ and $\left.A_{S+A P T E S+A g} \cdot\right]$

potável para consumo humano [16-20]. Em particular, os resultados foram similares aos obtidos em [12] para substratos cerâmicos tratados com APTES. Assim, tanto para o uso de APTES quanto para o emprego alternativo de EDTA, como sugerido neste trabalho, não houve detecção de $E$. Coli após a exposição ao substrato cerâmico impregnado com nanoprata.

Um provável mecanismo de conexão de APTES com nanoprata foi sugerido a partir da hidrólise e formação de grupos $\mathrm{OH}$ (3 unidades por molécula), os quais têm afinidade com a superfície do substrato cerâmico [12]. Por analogia, como resumido na Tabela V, o EDTA apresenta 4 grupos $\mathrm{OH}$ por molécula. Além disso, sabe-se que grupos $\mathrm{NH}_{2}$ podem coordenar com átomos de $\mathrm{Ag}$, pois a prata apresenta um orbital vazio e o N um par disponível de elétrons [21]. A molécula de APTES tem somente um átomo de nitrogênio, ao passo que o EDTA apresenta 2 átomos de $\mathrm{N}$ por molécula. Assim, sugere-se que a maior disponibilidade de átomos responsáveis pela conexão com a superfície cerâmica e com a nanoprata permite ao EDTA um desempenho equivalente, ou eventualmente superior, ao APTES. Recentemente, o papel do EDTA na estabilização de nanopartículas de prata foi investigado e atribuído ao efeito quelante [22]. A combinação EDTA/Ag mostrou, também nesse caso, uma destacada atividade antimicrobiana. Por fim, mas não menos importante, uma vantagem no uso de EDTA ao invés de APTES é o seu menor custo relativo.

\section{CONCLUSÕES}

Oatual trabalho avaliou a modificação superficial de filtros cerâmicos com EDTA e APTES para melhor impregnação da prata e consequentemente um melhor desempenho e tempo de vida do elemento filtrante. Têm-se como principais conclusões que ambos os tratamentos melhoraram a captura da prata pela cerâmica e que a ancoragem da prata com EDTA foi mais bem sucedida na impregnação do substrato inteiro. Isto indicou que se pode obter uma melhor fixação da prata pela cerâmica através de um reagente mais acessível e através de uma rota simples de modificação superficial. Também se concluiu que a ordem na sequência das etapas de impregnação na cerâmica é indiferente quanto ao resultado final. Quanto à avaliação da atividade bactericida dos substratos, a análise de filtração de amostras de água contaminadas com Escherichia coli permitiu concluir que todos os substratos que foram impregnados com prata, fossem eles ancorados ou não, apresentaram a ausência deste coliforme termotolerante em $100 \mathrm{~mL}$ de amostra, padrão este usado como referência de potabilidade da água. Desta forma, concluiu-se que o procedimento de impregnação por imersão em soluções nanocoloidais de prata atingiu o efeito bactericida esperado e que os tratamentos de ancoragem não interferiram na atuação microbiológica dos filtros.

\section{AGRADECIMENTOS}

Os autores agradecem ao $\mathrm{CNPq}$ pela concessão de auxílio financeiro para o desenvolvimento deste trabalho, e à empresa TNS (TechNano Solution) pelo fornecimento de amostras de prata coloidal.

\section{REFERÊNCIAS}

[1] World Health Org., "UN-water global analysis and assessment of sanitation and drinking-water", UNO/WHO, Geneva (2014).

[2] Secr. Nac. Saneam. Amb., Sist. Nac. Infor. Saneam.,

Tabela V - Análise comparativa de APTES e EDTA.

[Table V - Comparative analysis of APTES and EDTA.]

\begin{tabular}{ccc}
\hline Composto & APTES & EDTA \\
\hline Número CAS & $919-30-2$ & $60-00-4$ \\
Fórmula linear & $\mathrm{H}_{2} \mathrm{~N}\left(\mathrm{CH}_{2}\right)_{3} \mathrm{Si}\left(\mathrm{OC}_{2} \mathrm{H}_{5}\right)_{3}$ & $\left(\mathrm{HO}_{2} \mathrm{CCH}_{2}\right)_{2} \mathrm{NCH}_{2} \mathrm{CH}_{2} \mathrm{~N}_{\left(\mathrm{CH}_{2} \mathrm{CO}_{2} \mathrm{H}_{2}\right.}$ \\
Fórmula estrutural & Líquido & Sólido (pó) \\
Massa molecular $(\mathrm{g} / \mathrm{mol})$ & 512,00 & 117,00 \\
Estado físico & 221,37 & 292,24 \\
Preço (USD/kg)* & &
\end{tabular}


"Diagnóstico dos serviços de água e esgotos 2013", SNSA, Brasília (2014).

[3] D. Lantagne, "Investigation of the Potters for Peace colloidal silver impregnated ceramic filter", USAID, Boston (2001).

[4] V.A. Oyanedel-Craver, J.A. Smith, Environ. Sci. Tech. 42, 3 (2008) 927.

[5] Y. Matsumura, K. Yoshikata, S. Kunisaki, T. Tsuchido, Appl. Environ. Microbiol. 69, 7 (2003) 4278.

[6] Q. Feng, J. Wu, G. Chen, F. Cui, T. Kim, J. Kim, J. Biomed. Mater. Res. 52 (2000) 662.

[7] J. Lalley, D. Dionysiou, R. Varma, S. Shankara, D. Yang, M. Nadagouda, Curr. Opin. Chem. Eng. 3 (2014) 25.

[8] S. Hussain, K. Hess, J. Gearhart, K. Geiss, J. Schlager, Toxicol. In Vitro 19, 7 (2005) 975.

[9] E. Navarro, F. Piccapietra, B. Wagner, F. Marconi, R. Kaegi, N. Odzak, L. Sigg, R. Behra, Environ. Sci. Tech. 42, 23 (2008) 8959.

[10] S. Archer, Can. J. Cardiol. 24, 5 (2008) 397.

[11] M. Fonseca, C. Airoldi, Quím. Nova 26, 5 (2003) 699.

[12] Y. Lv, H. Liu, Z. Wang, S. Liu, L. Hao, Y. Sang, D. Liu, J. Wang, R.I. Boughton, J. Membr. Sci. 331 (2009) 50.

[13] A. Yildiz, A. Gür, J. Serb. Chem. Soc. 72, 5 (2007) 467.
[14] S. Hashemian, M. Shahedi, J. Chem. 2013 (2013) 1. [15] Minist. Saúde, "Portaria 518/MS/GM 25/03/2004", M.S., Brasília (2004).

[16] D. van Halem, H. van der Laan, S.G.J. Heijman, J.C. van Dijk, G.L. Amy, Phys. Chem. Earth 34 (2009) 36.

[17] A.R. Bielefeldt, K. Kowalski, R.S. Summers, Water Res. 43 (2009) 3559.

[18] A.M. Gutierrez, D. Hotza, G.B. Dutra, A.L. Nogueira, C.V. Franco, W. Acchar, C.R. Rambo, Mater. Sci. Forum 798-799 (2014) 727.

[19] H. van der Laan, D. van Halem, P.W. Smeets, A.I. Soppe, J. Kroesbergen, G. Wubbels, J. Nederstigt, I. Gensburger, S.G. Heijman, Water Res. 15, 51 (2014) 47.

[20] T.M. Amadio, D. Hotza, J.B. Rodrigues Neto, M. Blosi, A.L. Costa, M. Dondi, Appl. Clay Sci. 146 (2017) 1.

[21] C. Gianni, M.M. Maurizion, J. Phys. Chem. B 106 (2002) 6875.

[22] J.M. Martinez-Andrade, M. Avalos-Borja, A.R. VilchisNestor, L.O. Sanchez-Vargas, E. Castro-Longoria, PLoS One 13, 1 (2018) e0190866.

[23] Sigma-Aldrich, www.sigmaaldrich.com, ac. 24/03/2019.

(Rec. 22/01/2019, Rev. 26/03/2019, Ac. 06/05/2019) 